\title{
Utilization of Rice Husk Ash in Reactive Powder Concrete
}

\author{
R.Sutharsan,PL.Meyyappan, M.AhamedAzik Ali
}

\begin{abstract}
Reactive Powder Concrete (RPC) is a special concrete with excellent mechanical and durability properties and it is differentiated with other forms of concrete in terms of production, mix proportion etc. Depending upon various parameters like composition and the curing temperature, its compressive strength ranges from $130 \mathrm{MPa}$ to $750 \mathrm{MPa}$, bending strength varies as 29 to $51 \mathrm{MPa}$ and Young's modulus results upto 50GPa to 75GPa.Though RPC possesses many outstanding properties, it has limited applications in the construction field. The usage of higher quantity of cement and Silica Fume causes the rise of production of RPC. In addition to that, the silica fume availability is also restricted. For a country like India, usage of SF is limited due to its high price. Also, mineral admixtures can be used as a suitable alternative. Hence in this research work, Rice Husk Ash (RHA) is used as a possible alternatives for replacing silica fume in RPC. RHA holds maximum amount of silica (approx. 96\%) in amorphous form. In this research, an experimental research on mechanical and durability properties of RPC by partially replacing $S F$ with $R H A$. The detailed literature survey on constituent materials, mix proportions and curing conditions of RPC were done. Also, the optimum temperature and duration for the thermal treatment of RHA were identified. The compressive strength of the specimens of partial replacement of Silica Fume using RHA were tested and the results were compared with control specimens compressive strength.
\end{abstract}

Key Words-Rice husk ash, Reactive powder concrete, Compressive strength, XRD, EDAX.

\section{1.INTRODUCTION}

Reactive Powder Concrete is a very high performance concrete with a very good characteristics in terms of strength and durability. In general, Reactive Powder Concrete is a fibre -reinforced, super plasticised, SF cement mixed with very fine quartz in presence of lower $\mathrm{W} / \mathrm{C}$ ratio. The compressive strength of 130 to $750 \mathrm{MPa}$ can be achieved depending on the composition and method of curing.

Revised Manuscript Received on December 05, 2019.

R.Sutharsan*, Department of Civil Engineering, Kalasalingam Academy of Research and Education, Krishnankoil, India. Email: r.sutharsan@klu.ac.in

PL. Meyyappan*, Civil department, Kalasalingam Academy of Research and Education, Krishnankoil, India. Email: meyyappan@klu.ac.in
Due to the non availability of coarse aggregate enhances the property of microstructure and helps in the performance of RPC. The addition of steel fibres helps to gain ductility strength and therefore steel reinforcement usage can be minimized or extincted. The conventional concrete has lesser durability and strength when compared to RPC. This status has been achieved by RPC because of its low water binding ratio which helps in very low porosity.

The high characteristic strength and durability helps the use of RPC in several practical applications such as high buildings, nuclear waste disposal and bridges with proper guidance of engineers.

Silica Fume (SF) is one of the major component in RPC. The pozzolonic reaction is much more initiated by using this silica fume. The silica fume has a behavior of extreme fineness and amorphous silica content which improves the process of hydration on reacting with lime. Due to the limited availability and higher cost of silica fume, it is not extensively used in developing countries. This makes to produce RPC with the minimum content of silica fume and gave the probability of finding suitable alternative materials which exhibits similar properties.

One of the substitution may be Rice Husk Ash (RHA), an agro waste product by burning rice husk. RHA is prepared by burning rice husk at suitable temperature under controlled conditions; The size of the particle ranges upto a maximum of $10 \mu \mathrm{m}$ whereas in case of SF it may go upto $1 \mu \mathrm{m}$.

\subsection{RHA- A Potential Alternative of SF}

Rice husk is a by-product obtained from rice paddy mill. It has the volume of $1 / 5^{\text {th }}$ of the total rice production in the world. The rice husk can be used as an admixture in concrete production of the construction industry. The usage helps in the disposal of the waste as a useful product because of its unique characteristics. This is mainly used in the construction industry because of its pozzolonic nature. The pozzolonic reaction is a major phenomenain which the

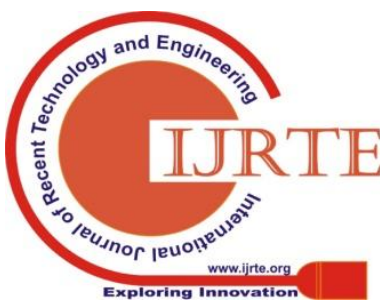




\section{Utilization of Rice Husk Ash in Reactive Powder Concrete}

construction field is searching for. This can be achieved by the presence of silica. The thermal activity and duration of the treatment helps to initiate the reaction with much more vigorous than its ideal one.The temperature normally we preferred would be $600^{\circ} \mathrm{C}$ for a limitation of 2 hours. RHA helps in the production of CSH gel.

Pierre Richard et al. (1995) conducted a research programme on the composition for RPC 200 and RPC 800 based on the basic principles of ultra-high strength ductile concrete. They concluded that thenon addition of coarse aggregate and an optimized mixture helps to form a strong binding cementious material which shows very good mechanical properties. Andres Salas et al (2009) investigated about production process of RHA. It was chemically treated before burning it. They found that the effectiveness of the RHA was improved when it was chemically treated before burning when compared to the thermally treated RHA (TRHA). The crystallization of silica in rice husks has been decreased by using acid treatment. Incorporation of Chemically treated RHA (ChRHA) in High-Performance Concrete enhances Compressive strength, flexural strength and also the durability properties by refining its pore structure. Nguyen van Tuan et al (2010) experimented the usageof RHA to produce Reactive Powder Concrete by replacing silica fume. RHA has a major composition of silica content and a wide area hence classified as " highly active pozzolan" and used as an alternative for silica fume. HalitYazici et al.(2013) studied about comparison of the mechanical properties in autoclave and standard water curing condition. The conclusion he attained that several parameters like pressure and temperature paves a major role in the behavior of RPC. Particularly for the compressive strength, the strength exceeds to $200 \mathrm{MPa}$. A.L.G.Gastaldini et al (2014) investigated the effects of RHA on mechanical and shrinkage properties as well as chloride penetration by replacing cement with SF and RHA. The concrete mixes for variying proportions of mixing of RHA were studied. In addition to that the experiment has been extended to three water to cement binding ratio for better understanding about the RPC. S.K. Antiohos et al (2014) investigated the cause and effect of addition of silica and well treated RHA in terms of all mechanical and durability properties of different forms of concrete. If if was ground to $7000 \mathrm{~cm}^{2} / \mathrm{kg}$ we can have very good results. Further grinding of RHA will improve mechanical and durability performance in concrete.

Retrieval Number: D10201284S219/2019@BEIESP DOI:10.35940/ijrte.D1020.1284S219

\section{EXPERIMENTS}

\subsection{Materials}

The RPC concrete mix uses the OPC grade of 53 cement was 53 Grade as per IS 12296-1987. The specific gravity was found to be 3.10 . The specific gravity of silica fume is in the order of 2.2 to 2.6. This helps for the better reaction of the silica fume with other materials and simultaneously which helps to improve the properties of the concrete.

Quartz sand of size less than $600 \mu \mathrm{m}$ is basically used. The particle size of the quartz used for the RPC is is $10 \mu \mathrm{m}$.

To improve the workability of fresh RPC high range water reducing poly-carboxylate based super plasticiser is added to the mixture.

RHA is utilized as a suitable alternative mineral admixture to replace the Silica Fume in RPC.

Steel fibres constitute a special inclusion in RPC. The straight steelfibres used were $16 \mathrm{~mm}$ length with a dia of $0.12 \mathrm{~mm}$. The fibres were inserted in the mixture of $2 \%$ of the volume of concrete. The volume of the fibre will not be increased because of its density.

TABLE 2.1.Physical properties of materials

\begin{tabular}{|c|c|}
\hline Constituent Materials & Specific Gravity \\
\hline Cement & 3.10 \\
\hline Silica Fume & 2.456 \\
\hline Quartz Sand & 2.597 \\
\hline Quartz Powder & 2.688 \\
\hline Rice Husk Ash & 2.154 \\
\hline
\end{tabular}

\subsection{Experimental methods}

In this study, the main constituent material of RPC namely silica fume is replaced by RHA at different proportions. The optimum temperature and time duration for thermal treatment of rice husk to produce

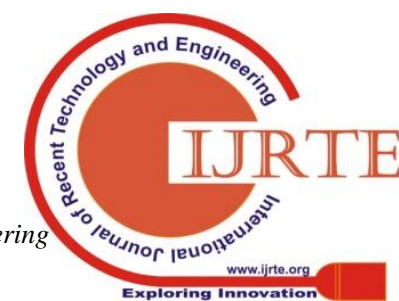


amorphous ash with maximum silica content were found. For this X-Ray diffraction (XRD) test was performed on RHA obtained at various temperature and duration of thermal treatment.

1. Temperatures: $550^{\circ} \mathrm{C}, 600^{\circ} \mathrm{C}, 650^{\circ} \mathrm{C}, 700^{\circ} \mathrm{C}$.

2. Durations : $1 \mathrm{hr}, 2 \mathrm{hrs}, 3 \mathrm{hrs}, 4 \mathrm{hrs}$.

The EDAX test was performed on amorphous RHA samples to find the constituents and silica content of the samples. The control specimens and specimens with RHA were cast and tested for the 7 days and 28 days compressive strength.

\section{Compresssive Strength}

The compression test was carried out to find out the compressive strength in concrete. The compressive strength of a concrete cube depends upon constituents, $\mathrm{w} / \mathrm{b}$ ratio, curing temperature, and proper shape of the cube. The cube specimen of standard size of $70.7 \mathrm{~mm} x$ $70.7 \mathrm{~mm}$ have been used. (as per IS: 516-1959) were cast for finding 7 days and 28 days compressive strength. The cubes were tested in

For each mix, 12 specimens (6 for normal curing and 6 for steam curing) were tested to find the strength for both 7 and 28 days.

\section{Processing of Rice HuskAsh}

Raw rice husk consist of several impurities and carbon content in the sample. This can be eliminated from the RHA by heating to a higher temperature under controlled conditions. Samples were collected for various temperatures of $500^{\circ} \mathrm{C}$ and $700^{\circ} \mathrm{C}$. For each temperature, samples were taken out for every 1 hour of duration up to 4 hours and hence the collected samples were named on the basis of time and temperature to which is to subjected.After the collection of samples it were sent for XRD at Alagappa University, Karaikudi and for EDAX at Karunya University, Coimbatore. The obtained XRD and EDAX are summarized below, from the values obtained best suitable sample was fixed.

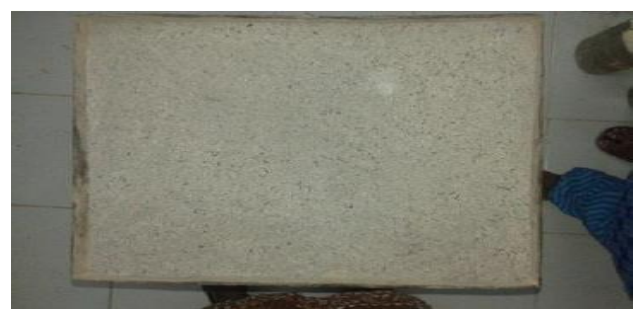

Fig 2.1: Treated Rice Husk Ash

\section{RESULTS AND DISCUSSION}

\subsection{The result of the combined effect of RHA and SF on the compressive strength of RPC}

Control specimen and specimens with silica fume replaced by RHA were tested for compressive strength in both 7 and 28 days. The test results of the specimen are shown in Table 3.1 and 3.2.

TABLE 3.1Compressive Strength of Specimen withRHA

RX -\% of Rice husk ask in the concrete

$\mathrm{SY}-\%$ of Silica fume in the concrete

\begin{tabular}{|r|l|l|l|}
\hline \multirow{2}{*}{$\begin{array}{l}\text { N. } \\
\text { No }\end{array}$} & $\begin{array}{l}\text { Specime } \\
n\end{array}$ & \multicolumn{2}{|l|}{$\begin{array}{l}\text { 2 DaysCompressive } \\
\text { Strength }\end{array}$} \\
\cline { 3 - 4 } & & $\begin{array}{l}\text { Normal } \\
\text { curing }\end{array}$ & $\begin{array}{l}\text { Steam } \\
\text { curing }\end{array}$ \\
\hline 1 & R10S90 & $150.35 \mathrm{MPa}$ & $163.32 \mathrm{MPa}$ \\
\hline 2 & R20S80 & $158.64 \mathrm{MPa}$ & $170.41 \mathrm{MPa}$ \\
\hline 3 & R30S70 & $172.78 \mathrm{MPa}$ & $185.63 \mathrm{MPa}$ \\
\hline 4 & R40S60 & $134.68 \mathrm{MPa}$ & $146.43 \mathrm{MPa}$ \\
\hline 5 & R50S50 & $125.61 \mathrm{MPa}$ & $138.94 \mathrm{MPa}$ \\
\hline
\end{tabular}

TABLE 3.2 Compressive Strength of Control Specimen

\begin{tabular}{|r|l|l|l|}
\hline $\begin{array}{l}\text { S. } \\
\text { No }\end{array}$ & $\begin{array}{l}\text { Curing } \\
\text { Condition }\end{array}$ & \multicolumn{1}{|c|}{7 Days } & \multicolumn{1}{|c|}{28 Days } \\
\cline { 3 - 4 } & $\begin{array}{l}\text { Compressive } \\
\text { Strength }\end{array}$ & $\begin{array}{l}\text { Compressive } \\
\text { Strength }\end{array}$ \\
\hline 1 & $\begin{array}{l}\text { Normal } \\
\text { curing }\end{array}$ & $114.3 \mathrm{MPa}$ & $136.9 \mathrm{MPa}$ \\
\hline 2 & $\begin{array}{l}\text { Steam } \\
\text { curing }\end{array}$ & $122.3 \mathrm{MPa}$ & $146.95 \mathrm{MPa}$ \\
\hline
\end{tabular}

The compressive strength of RPC does not significantly decrease up to $30 \%$ replacement of Silica Fume by RHA.

\subsection{XRD and EDAX of RHA on RPC}

The XRD and EDAX tests were carried out for different temperatures $\left(550^{\circ} \mathrm{C}\right.$ to $\left.700^{\circ} \mathrm{C}\right)$ for a duration variation from 1 hour to 4 hour with an interval of 1 hour duration.

The test analysis results are shown below. 


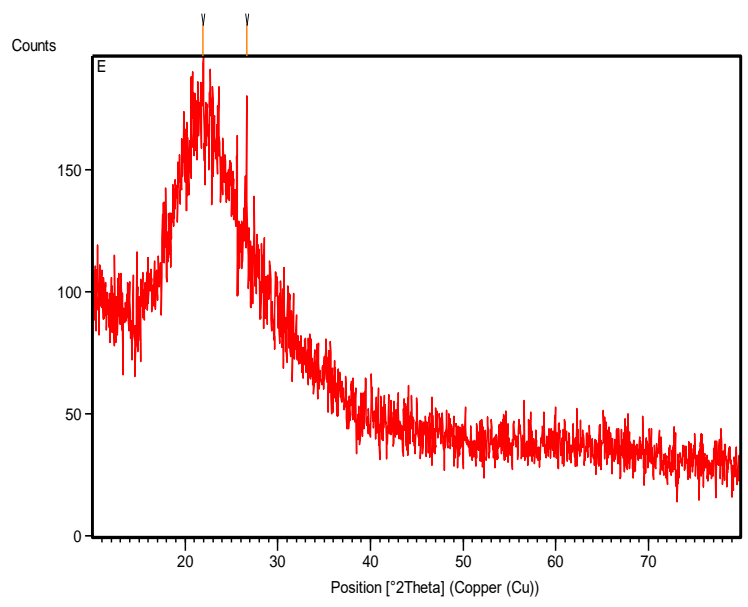

Fig 3.1 XRD of RHA at $600^{\circ} \mathrm{C}-2 \mathrm{Hrs}$.

TABLE 3.3 EDAX of RHA at $600^{\circ} \mathrm{C}-2 \mathrm{Hrs}$

\begin{tabular}{|l|l|}
\hline Element & Weight\% \\
\hline O k & 47.71 \\
\hline Si k & 45.80 \\
\hline C k & 5.56 \\
\hline K k & 0.81 \\
\hline Al k & 0.11 \\
\hline
\end{tabular}

From the XRD values, the refraction of the chemical properties were analysed whether it was an amorphous state or in the crystalline state. The arrangement of the atoms in the disorder manner is due to the refraction and diffraction properties is due to the amorphous state and if it is in orderly manner it shows the crystalline nature. evenif the silica content is more those conditions will not be selected for treating Rice husk.

The RHA obtained at the different burning conditions of $550^{\circ} \mathrm{C}$ to $700^{\circ} \mathrm{C}$ temperatures at $1 \mathrm{hr}, 2 \mathrm{hrs}, 3 \mathrm{hrs}$ and 4hrs duration were having their arrangement of atoms in disorder manner during diffraction and hence the nature of these RHA were purely amorphous in nature.From EDAX test results of amorphous RHA samples, the RHA of $600^{\circ} \mathrm{C}$ at $2 \mathrm{hrs}$ duration exhibit the maximum silica content of $45.80 \%$ by weight with a minimum carbon content of $5.56 \%$.

The RHA of $550^{\circ} \mathrm{C}$ at $1 \mathrm{hr}$, RHA of $550^{\circ} \mathrm{C}$ at $2 \mathrm{hrs,}$ RHA of $550^{\circ} \mathrm{C}$ at $3 \mathrm{hrs}$ and RHA of $550^{\circ} \mathrm{C}$ at $4 \mathrm{hrs}$ were having the minimum silica content $34.07 \%, 34.42 \%$, $34.42 \%$ and $35.36 \%$ and carbon content $2.68 \%, 4.70 \%$, $4.70 \%$ and $1.27 \%$ respectively. The RHA of $600^{\circ} \mathrm{C}$ at $1 \mathrm{hr}$ and RHA of $600^{\circ} \mathrm{C}$ at $2 \mathrm{hrs}$ were having the silica content $33.00 \%$ and $41.96 \%$ and carbon content $0 \%$ and $5.56 \%$ respectively.

The silica content of RHA of $650^{\circ} \mathrm{C}$ at $1 \mathrm{hr}$, RHA of $650^{\circ} \mathrm{C}$ at $2 \mathrm{hrs}$, RHA of $650^{\circ} \mathrm{C}$ at $3 \mathrm{hrs}$ and RHA of $650^{\circ} \mathrm{C}$ at $4 \mathrm{hrs}$ were $40.15 \%, 40.25 \%, 37.94 \%$ and $39.84 \%$ respectively without carbon content.

Retrieval Number: D10201284S219/2019@BEIESP DOI:10.35940/ijrte.D1020.1284S219
The RHA of $700^{\circ} \mathrm{C}$ at $1 \mathrm{hr}$, RHA of $700^{\circ} \mathrm{C}$ at $2 \mathrm{hrs}$, RHA of $700^{\circ} \mathrm{C}$ at $3 \mathrm{hrs}$ and RHA of $700^{\circ} \mathrm{C}$ at $7 \mathrm{hrs}$ were having the silica content $37.18 \%, 41.71 \%, 39.37 \%$ and $39.35 \%$ respectively without carbon content.

The RHA of $600^{\circ} \mathrm{C}$ at $4 \mathrm{hrs}$ were having the minimum silica content of $14.93 \%$ by weight and maximum carbon content of $8.93 \%$ by weight.

This test results show that RHA which has $600^{\circ} \mathrm{Cfor} 2$ hours shows amorphous ash with maximum silica content and lower carbon content.

\section{CONCLUSION}

The properties of RPC and RHA was studied and the constituent materials of RPC, mix proportioning of RPC and the temperature and duration for controlled burning of rice husk and also the influence of properties of RHA and SF on RPC were analysed. Inclusion of RHA does not have much impact on the decrease of the compressive strength of RPC compared to that of SF, RHA is added and also the combination of SF and RHA can increase the total cement replacement percentage up to $40 \%$ to produce RPC.

By XRD and EDAX analysis, the optimum temperature and duration were found out for burning rice husk to obtain amorphous ash with maximum silica content. The amorphous ash with maximum silica content obtained at $600^{\circ} \mathrm{C}$ for 2 hours gave the convincing result for the silica fume replacement.

The addition of RHA does not significantly decrease the compressive strength of RPC compared to that of SF, when less than $30 \%$ RHA is added.The steam curing enhances the compressive strength which provides an additional support to the improvement of the strength.

The Strength pattern of RHA and silica fume mixed concrete shows the increased value at a certain level( $30 \%$ Flyash and $70 \%$ Silica fume) and it decreases. Further analysis of materials if some additive admixtures and the improvement of the reaction of the materials within them paves the strength of the material

\section{Acknowledgement}

The authors would like to express gratefulness for the Department of Nanoscience and Technology, Karunya University \& Department of Physics, Alagappa University for their valuable support for XRD and EDAX analysis of RHA.

\section{REFERENCES}

1. Andres Salas ,Silvio Delvasto, Ruby Mejía de Gutierrez, David Lange (2009), 'Comparison of two processes for treating rice husk ash for use in high performance concrete', Cement

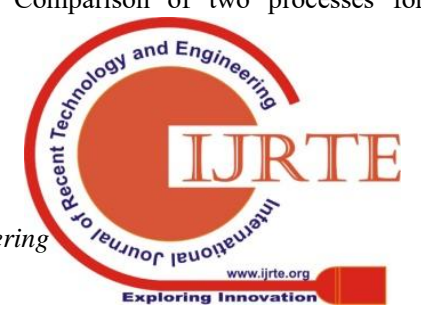


and Concrete Research, Vol.39, pp. 773-778

2. AmbilyP.S,UmaraniC,RavisankarK,PrabhatRanjanPrem, BharatkumarB.H,NageshR.Iyer(2015), 'Studiesonultra highperformanceconcreteincorporatingcopperslagasfine aggregate',Construction and Building Materials, Vol.77,pp.233-240

3. Antiohos S.K, Papadakis V.G, Tsimas S (2014), 'Rice husk ash (rha) effectiveness in cement and concrete as a function of reactive silica and fineness', Cement and Concrete Research , Vol.61, pp. 20-27.

4. CaijunShi,DehuiWang,LinmeiWu,ZemeiWu(2015), 'The hydrationandmicrostructureofultrahigh-strengthconcretewith cement-silicafume-slagbinder',Cement \& Concrete Composites, Vol.61,pp.44-52.

5. GastaldiniA.L.G,daSilvaM.P,ZamberlanF.B,Mostardeiro NetoC.Z(2014), 'Totalshrinkage, chloridepenetration, and compressivestrengthofconcretesthatcontainclear-coloredrice huskash',Construction and Building Materials, Vol.54,pp.369-377.

6. HalitYazici,EnginDeniz,BulentBaradan(2013), 'Theeffectof autoclavepressure,temperatureanddurationtimeonmechanical propertiesofreactivepowderconcrete',Construction and Building Materials, Vol.42,pp.53-63.

7. HalitYazici,MertYucelYardimci,SerdarAydin,AnilS.Karabul ut(2009), 'MechanicalPropertiesofReactivePowder ConcreteContainingMineralAdmixturesunderDifferent CuringRegimes',Construction and Building Materials journal, Vol.29,pp.1223-1231.

8. HuseyinYigiter,SerdarAydin,HalitYazici,MertYuce Yardimci(2012), 'Mechanicalperformanceoflowcement reactivepowderconcrete(LCRPC)',Composites: B ,Vol43,pp.2907-2914.

9. LapyotePrasittisopin,DavidTrejo(2015),'Hydrationandphase formationofblendedcementitioussystemsincorporating chemicallytransformedricehuskash',Cement \& Concrete Composites, Vol.59,pp.100-106.

10. [10] NguyenVanTuan,GuangYe,KlaasvanBreugel,Oguzhan Copuroglu(2011), 'Hydrationandmicrostructureofultrahigh performanceconcreteincorporatingricehuskash',Cement and Concrete Research, Vol.41,pp.1104-1111.

11. NguyenVanTuan,GuangYe,KlaasvanBreugel,AlexL.A.Fraaij ,BuiDanhDai(2011),'Thestudyofusingricehuskashtoproduceu ltrahighperformanceconcrete',Construction andBuilding Materials, Vol.25,pp.2030-2035.

12. PierreRichard,MarcelCheyrezy(1995), 'Compositionof ReactivePowderConcrete',Cement and Concrete Research Journal,Vol.25.No.7,pp.1501-1511.

13. Viet-Thien-AnVan,ChristianeRößler,Danh-DaiBui,HorstMichaelLudwig(2014), 'Ricehuskashasbothpozzolanic admixtureandinternalcuringagentinultra-highperformance concrete',Cement \& Concrete Composites, Vol.53,pp.270-278.

14. WenzhongZheng,BaifuLuo, YingWang(2013),'Compressive andtensilepropertiesofreactivepowderconcretewithsteel fibresatelevatedtemperatures',Construction and Building Materials, Vol.41,pp.844-851.

15. YuR,SpieszP,BrouwersH.J.H(2015), 'Developmentofan eco-friendlyUltra-HighPerformanceConcrete(UHPC)with efficientcementandmineraladmixturesuses',Cement $\&$ Concrete Composites, Vol.55,pp.383-394

16. PL. Meyyappan, K.Kumaran, M.Gopalakrishnan and E. Harikrishnan (2018), "Effect of glass fibers, flyash and quarry ash on Strength and Durability Aspects of Concrete - An Experimental Study", IOP Conference Series: Material Science and Engineering, doi:10.1088/1757-899X/396/1/012001.

17. PL. Meyyappan, K.Kumaran, M.Gopalakrishnan and E. Harikrishnan (2018), "Experimental Investigation on the Effect of Silica fume and Pumice stone in Developing Light Weight Concrete", IOP Conference Series: Material Science and Engineering, doi:10.1088/1757-899X/561/1/012064.

18. PL. Meyyappan, P. Amuthakannan, R. Sutharsan and M. Ahamed Azik Ali (2019), "Utilization of M-Sand \& Basalt
Fiber in Concrete: An Experimental Study on Strength and Durability Properties", IOP Conference Series: Material Science and Engineering, doi:10.1088/1757-899X/561/1/012035.

\section{AUTHORS PROFILE}

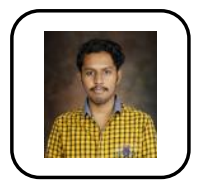

Mr. R. Sutharsan completed his M.E in Structural Engineering in Thiagarajar College of Engineering, Madurai in the year 2016. He completed his Bachelor of Engineering under Anna University in the year 2013. He is working as Assistant Professor in Department of Civil Engineering at Kalasalingam University, Tamilnadu, India. His main thrust research areas is Fiber reinforced concrete.

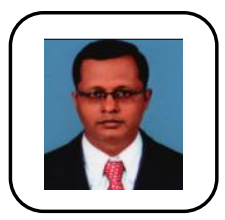

Dr. PL. Meyyappanhas completed his graduation and post-graduation from Bharathiyar University and Karunya University respectively. $\mathrm{He}$ completed his $\mathrm{PhD}$ from Kalasalingam University. $\mathrm{He}$ has 13 years of teaching experience. He has completed 2 sponsored research projects from TNSCST and published more than 25 papers in peer reviewed journals and conferences. He is a life member in ISTE, IEI, IGS, ISET, ISRS. He is serving as Editorial Board Member and Reviewer in various reputed Journals. 